\title{
The effect of peer support in adults with insulin pump-treated type I diabetes: a pilot study of a flexible and participatory intervention
}

This article was published in the following Dove Press journal:

Patient Preference and Adherence

2 November 2017

Number of times this article has been viewed

\author{
Lene Eide Joensen' \\ Merete Meldgaard \\ Andersen ${ }^{2}$ \\ Sabrina Jensen' \\ Kirsten Nørgaard ${ }^{2}$ \\ Ingrid Willaing'
}

'Diabetes Management Research, Steno Diabetes Center Copenhagen, Gentofte, ${ }^{2}$ Department of

Endocrinology, Hvidovre Hospital, Hvidovre, Denmark
Correspondence: Lene Eide Joensen Diabetes Management Research, Steno Diabetes Center Copenhagen, Niels Steensens Vej 6, 2820 Gentofte, Denmark

Tel +45 309| 3293

Email lene.eide.joensen@regionh.dk
Aim: The aim of this study was to explore the effects of a flexible and participatory peer support intervention in a clinical setting for adults with type 1 diabetes treated with an insulin pump, focusing on enhancing diabetes-specific social capital. The key questions were as follows: 1) what effects are appropriate to expect, according to participants? and 2) to what extent did these effects occur?

Methods: Two peer support intervention programs were conducted in a diabetes specialist clinic $(\mathrm{N}=30)$. A participatory and adaptable approach allowed flexibility in the content of peer support meetings, which were facilitated by a diabetes nurse. Individual interviews explored participants' perception of effects of the intervention. Interview data were analyzed qualitatively. Participants ( $\mathrm{n}=27)$ completed a baseline and postintervention questionnaire that included items assessing diabetes empowerment, diabetes distress, diabetes-specific social support, and diabetes loneliness. HbA1c levels were compared before and after the intervention.

Results: Participants experienced enhanced diabetes-specific social capital, diabetes motivation, awareness of personal diabetes practices, and serenity and openness in life with diabetes. They also became more aware of treatment and support possibilities. Negative effects included feeling sad or upset after the meetings or feeling different than and not as well-controlled as other participants. Quantitative analyses showed enhanced social support, decreased eating distress and trends toward enhanced diabetes empowerment, decreased diabetes loneliness, and decreased diabetes distress (powerlessness). We found fewer positive and/or negative outcomes among participants who felt no need for peer support or felt that the group was not a unit or that important issues were not addressed.

Conclusion: The study indicated that flexible and participatory peer support can strengthen diabetes-specific social capital and improve participants' well-being and diabetes empowerment. Awareness of participants' incentives for attending peer support, as well as the risk of people feeling isolated within peer support groups, is essential to creating effective diabetes-specific social support.

Keywords: type 1 diabetes mellitus, insulin pump therapy, psychosocial support, psychological well-being, empowerment, exploratory research

\section{Introduction}

Insulin pump therapy is increasingly used for insulin replacement in both children and adults with type 1 diabetes. ${ }^{1-3}$ Compared to treatment with multiple injection therapy, insulin pump therapy has shown significant improvement in glucose control, a decrease in occurrence of severe hypoglycemia, less glucose variability, and improvement in treatment satisfaction. ${ }^{4}$ However, treatment by insulin pump requires patients to have 
specific competencies, such as carbohydrate counting for all meals and frequent blood glucose testing. A high percentage of insulin pump users use additional devices for continuous glucose monitoring (CGM), which requires extra efforts to cope with calibration, alarms, and the like. Adjustment to being connected to a device $24 / 7$ can be difficult. ${ }^{5}$ In general, people with diabetes often experience psychosocial problems, and $20 \%-30 \%$ of people with type 1 diabetes have elevated diabetes distress, which affects their ability to cope with and manage diabetes. ${ }^{6}$ Previous studies have indicated that lack of social support is associated with lower psychological wellbeing, as well as difficulties in managing diabetes and poorer glycemic control in people with type 1 diabetes. ${ }^{7,8}$ People using insulin pumps may benefit from social support focused on living with this treatment modality. Peer support is a method for providing diabetes-specific social support and has been found to be an effective method for providing emotional support and ongoing self-management. ${ }^{9}$

The literature on diabetes-specific peer support includes a wide range of peer interactions and interventions. The evidence is insufficient to determine which types of peer interactions, peer support elements, and interventions are most effective and applicable in different populations of people with diabetes. ${ }^{10}$ The rationale for peer support originates from social support theory. ${ }^{11}$ In the framework of the "direct effect model," social support from peers directly influences health by increasing positive emotions and individual motivation and decreasing loneliness. ${ }^{11}$ Peer support provides expanded access to information that may positively influence behaviors. The "buffering effect model" theorizes that peer support buffers the influence of stress on health through, for example, broadening coping strategies. ${ }^{11}$ Furthermore, within "the mediating effect model", peer support indirectly influences health by enhancing self-efficacy through mechanisms such as role modeling from someone similar. ${ }^{11}$

To the best of our knowledge, no study has explored the effects of peer support for adults with type 1 diabetes receiving insulin pump treatment. A previous study at Steno Diabetes Center found that peer support groups facilitated by health care professionals reduced diabetes distress among young adults with type 1 diabetes. ${ }^{12}$ In another study among young adults with type 1 diabetes that also included support from a health care professional, participation in peer support groups was associated with improved HbAlc levels and decreased diabetes burden. ${ }^{13}$ An exploratory qualitative study revealed that peer support among adults with type 1 diabetes both legitimized and relieved a shared and burdensome feeling of diabetes loneliness. ${ }^{14}$ The same study also identified peer support in type 1 diabetes as a way of enhancing the establishment and strength of diabetes-specific social capital. Notably, peer support fosters social support between individuals (giving and receiving social support) and creates space for genuine trust and a feeling of communality. ${ }^{14}$ The study also highlighted that peer support is particularly relevant in specific situations, such as having an insulin pump. Very specific treatment regimen is required when treated with insulin pump, which also points to benefits of peer support provided exclusively to people in insulin pump treatment, thereby enhancing the feeling of communality.

The concept of diabetes-specific social capital constitutes a wider perspective on the influence of social setting and social relations in diabetes self-management. Patients perceived preferred support from peers as very different from both support from health care professionals and structured education. ${ }^{14}$ Participatory methods, such as dialogue tools, provided a useful framework for creating diabetes-specific social capital among adults with type 1 diabetes. ${ }^{15}$

Dialogue tools include, eg, quotes from patients, photos taken by patients, postcards filled out by patients during the meetings, and cards with more general "openers" such as "I feel it is difficult when...". Dialogue tools are used to generate reflection and discussion and are inspired by cultural probes. Cultural probes were initially used in the design world and in ethnographic studies as an explorative method to strengthen active involvement, which leads to comprehensive insights into a person's life. ${ }^{16,17}$ Probes are intended to engage and even provoke participants to enter into dialogues and verbalize their experiences. ${ }^{16}$

Studies have shown that some groups of people with diabetes benefit more from peer support than others; for example, peer support has been found to be particularly beneficial among patients with low diabetes support in everyday life or low individual literacy levels. ${ }^{18}$ However, studies of peer support often fail to explore the characteristics of participants who benefit from peer support or the mechanisms underlying effective peer support. A crucial aspect of piloting relevant support interventions is the choice of appropriate outcome measures. ${ }^{19}$

In preparation of future effectiveness studies of peer support, the aim of the present pilot study was to explore potential effects of a flexible and participatory peer support intervention in a clinical setting for adults with insulin pump-treated type 1 diabetes, focusing on enhancing diabetes-specific social capital. The key questions were as follows: 1) what effects are appropriate to expect, according to participants? and 2) to what extent did these effects occur? 
In addition, the study explored effective elements of the peer support intervention and characteristics of participants who benefited from the intervention.

\section{Methods Intervention}

The peer support intervention consisted of four peer support meetings that took place in an outpatient setting at Hvidovre Hospital and relied on a participatory approach that encouraged flexible content. The meetings involved customized use of participatory methods, such as participants taking photos of their daily lives with type 1 diabetes and the insulin pump and sharing and discussing them with peers.

The intervention was tested in two support groups that each met four times for 3 hours each time over 4 months (September to December 2015). The first meeting involved participants in planning the content of the four peer support meetings, which were facilitated by a diabetes nurse. The meetings were held in the late afternoon, and a meal was served at every meeting. Table 1 shows examples of participatory tools used at the meetings.

\section{Participants}

We aimed for $\sim 15$ people to participate in each peer support group. Of the 182 available participants with type 1 diabetes treated with an insulin pump at Hvidovre Hospital, 29 participants were excluded because they lived too far away to attend peer support meetings, had previously reported that they did not want to participate in research projects, were not currently being treated via an insulin pump, did not speak Danish, and had comorbidities precluding participation. The remaining 153 participants were contacted via email (72), a secure mail service (40), letter (6), and during clinic visits (2). Of the 120 those contacted, 57 individuals did not respond to the invitation and 15 individuals did not state the reason for not wanting to participate. Others declined for reasons that included living too far away (5), travel plans during the study period (3), illness (29), lack of interest in meeting peers (5), lack of childcare (5), and wanting to take a break from treatment via an insulin pump (1).

Of the 33 individuals who wanted to participate in the peer support groups, three individuals did not appear at meetings. Thus, the study sample consisted of 30 participants with type 1 diabetes treated with insulin pump. The number of participants at each meeting varied between 11 and 15 (17 participants attended all four meetings, nine participants attended three meetings, and three participants attended two meetings). At the first meeting, confidentiality among participants was discussed. Both groups agreed on confidentiality in that no names or specific experiences should be passed on. However, some participants did find it important to be able to share experiences and information from the group anonymously to others that could benefit, eg, children and friends with diabetes and family members. Both groups agreed upon this. Written informed consent of study participation was obtained from all participants. Information included the purpose of the research study and data confidentiality and anonymity according to Danish law. It was stressed that participation was voluntary and that it was possible to withdraw at any stage. The study was approved by the Danish Data Protection Agency (SDC-2015-031 PEER). The Danish Committee on Health Research Ethics assessed that it was not necessary to register the project according to the Danish Act on Research Ethics Review of Health Research Projects (H-4-2015-FSP). No reimbursement was provided to the participants.

\section{Outcomes of interest}

We assessed participants' perceptions of potential effects and their self-reported effects on psychological well-being and diabetes empowerment and objectively measured glycemic control. Audio recordings of group discussions and observations were primarily used to map the process and content of peer support, but they also included participant perspectives on the effects of the peer support meetings. Semistructured individual interviews $1-3$ months after the final peer support meeting with 25 of 30 participants were used to explore how participants perceived the effects of the peer support meetings. Five participants did not respond to the request for an interview or were too busy.

Participants completed questionnaires before and after the four peer support meetings to evaluate the effect of the meetings on social support, psychological well-being, and empowerment. The questionnaire included items from validated scales that measured well-being (5-item World Health Organization Well-Being Index $)^{20,21}$ and diabetes distress (Type 1 Diabetes Distress Scale [T1-DDS]), which included the subdomains of powerlessness, negative social perceptions, physician distress, friend/family distress, hypoglycemia distress, management distress, and eating distress. ${ }^{22}$ Diabetes empowerment was measured using the Diabetes Empowerment Scale-Short Form. ${ }^{23}$ Diabetes-related social support from family, friends, people at work, health care professionals, and other people in the community was measured with the Diabetes Attitudes, Wishes and Needs (DAWN) support for diabetes self-management profile. ${ }^{24}$ A question about support from people with type 1 diabetes was developed by 
Table I Dialogue tools and exercises

\begin{tabular}{|c|c|c|}
\hline $\begin{array}{l}\text { Tool/ } \\
\text { exercise }\end{array}$ & Illustration & Aim and description \\
\hline Who am I? & $b$ & $\begin{array}{l}\text { Aim: to give participants the opportunity to introduce } \\
\text { themselves to each other by selecting pictures with different } \\
\text { associations } \\
\text { Description: when participants choose a picture and say } \\
\text { precisely why it is relevant, it enables them to talk about } \\
\text { other aspects of themselves than they usually do. The } \\
\text { exercise also enables participants to discover possible } \\
\text { common interests and to laugh together } \\
\text { Use: as an introduction at the first meeting }\end{array}$ \\
\hline $\begin{array}{l}\text { Question } \\
\text { sheet }\end{array}$ & & $\begin{array}{l}\text { Aim: to address and discuss topics relevant to participants } \\
\text { Description: participants individually write down questions } \\
\text { regarding specific topics they want to ask other people about } \\
\text { Use: as a starting point for discussions } \\
\text { during meetings }\end{array}$ \\
\hline $\begin{array}{l}\text { My social } \\
\text { relationships }\end{array}$ & $\begin{array}{l}\text { My social relationships } \\
\text { Please complete the six incomplete sentences } \\
\text { with the first thing that comes to mind. } \\
\text { I get good support from... } \\
\text { I get too little support from... } \\
\text { People who know how I live feel that I... } \\
\text { I think my friends think... } \\
\text { It irritates me when other people... } \\
\text { I am pleased when other people... }\end{array}$ & $\begin{array}{l}\text { Aim: to help participants gain insights into and clarify their } \\
\text { experiences and needs with respect to how those around } \\
\text { them react to them as individuals with a chronic condition } \\
\text { Description: participants are asked to complete sentences in } \\
\text { which the first word relates to their social relationships } \\
\text { Use: participants discussed their challenges during meetings }\end{array}$ \\
\hline Postcard & $\begin{array}{l}\text { If you should pass on an important } \\
\text { experience to a person with type } \\
\text { I diabetes and insulin pump, } \\
\text { what would it be? } \\
\end{array}$ & $\begin{array}{l}\text { Aim: to help participants reflect on what good advice } \\
\text { they feel that it would be important to give to others } \\
\text { in insulin pump treatment } \\
\text { Description: participants take the "postcard" and a brief } \\
\text { instruction home. They can reflect on the questions until the } \\
\text { next session and can also fill in the postcards } \\
\text { Use: participants discussed their questions in group meetings }\end{array}$ \\
\hline $\begin{array}{l}\text { Photo } \\
\text { exercise }\end{array}$ & 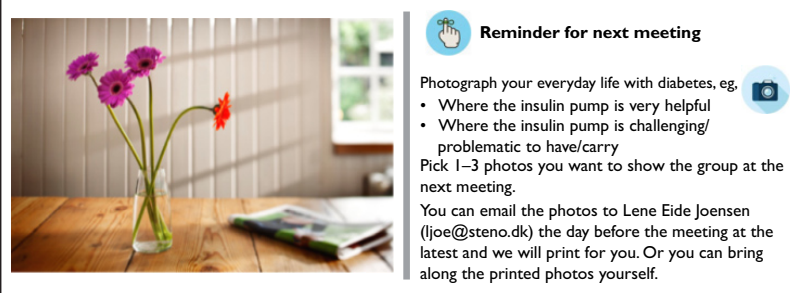 & $\begin{array}{l}\text { Aim: to help participants share concrete experiences from } \\
\text { everyday life } \\
\text { Description: participants were asked to take photos of } \\
\text { challenges and successes with the insulin pump in everyday life } \\
\text { with diabetes and bring the photos to the next meeting } \\
\text { Use: participants shared and discussed their photos in group } \\
\text { meetings }\end{array}$ \\
\hline $\begin{array}{l}\text { Dialogue } \\
\text { tool }\end{array}$ & $3_{0}^{P A E R . . .}$ & $\begin{array}{l}\text { Aim: to enhance and ease dialogue between participants } \\
\text { Description: the cards are used as "openers" in } \\
\text { dialogues on optional topics between peers } \\
\text { The first thing that comes to my mind is... } \\
\text { I would like to focus on... } \\
\text { I like it most when... } \\
\text { I think it is difficult when... } \\
\text { Use: participants used the tool during group meetings }\end{array}$ \\
\hline
\end{tabular}

Note: Copyright $\odot 20$ II Steno Diabetes Center Copenhagen. Images used in the table reproduced from Engelund G, Vinther-Andersen N, Hansen UM, Willaing I. In balance with chronic illness. Tools for patient education. Gentofte, Denmark: Steno Diabetes Center Copenhagen. ${ }^{38}$ 
the authors and included. Measures of general loneliness and diabetes-related loneliness were also included; general loneliness was measured by the Three-Item Loneliness Scale (TILS), ${ }^{25,26}$ and diabetes-related loneliness was measured by questions developed for this study, inspired by the TILS. We also developed questions about perceived support from people with type 1 diabetes and questions about the degree to which it was important to have contact with people with type 1 diabetes, inspired by the Diabetes Support Scale. ${ }^{27}$ Questions from the Danish National Health Survey about household composition and educational level were included. ${ }^{28}$ The entire questionnaire was pilot tested among five people with type 1 diabetes receiving insulin pump treatment before the study.

Supplementary open-ended questions about perceived effects of the intervention were included in the questionnaire given to participants after the four meetings. Finally, participants were asked to identify which of the included questionnaire domains (ie, well-being, diabetes distress, diabetes empowerment, diabetes-related social support, general loneliness, diabetes-related loneliness, and type 1 diabetes support) were most relevant for assessing the effect of peer support in type 1 diabetes.

HbA1c was measured at baseline and after the intervention, using the routine measures closest to the first meeting and closest to 6 months after the intervention. Baseline $\mathrm{HbA} 1 \mathrm{c}$ measurements were taken between 3 weeks before and 2 weeks after the first meeting. The interval between the end of the intervention and the next routinely measured HbA1c was 14-40 weeks (median 26, IQR 12 weeks).

\section{Analyses}

Qualitative data were analyzed with a focus on 1) participants' perceptions on the effects of the peer support meetings and 2) characteristics of the participants and the intervention that were associated with perceived effects. The analysis also included assessment of the topics that participants chose to discuss because they were expected to influence the perceived effect. Participant interviews, group discussions, and open-ended questions in the questionnaire were analyzed by systematic text condensation by dividing all text into meaning units and sorting related units into subthemes related to the predetermined focus areas. ${ }^{29}$ In order to explore group difference, data from the two peer support groups were first analyzed separately and then pooled.

Quantitative analyses of questionnaire data focused on 1) potential effects and 2) identification of relevant effect measures. Potential effects on HbA1c, well-being, diabetes empowerment, diabetes distress, and experiences of social support from the intervention were studied by comparing mean
$\mathrm{HbA} 1 \mathrm{c}$ and well-being scores and the proportion of participants with high diabetes distress and low diabetes empowerment with experiences of social support from peers (the proportion experiencing peers as very/somewhat supportive and being able to a very high/high degree to contact peers), generic loneliness, and diabetes loneliness before and after the peer support meetings. The Wilcoxon signed-rank test and paired $t$-tests were used to explore differences before and after the intervention. Data regarding participants' prioritizations of effect measures were analyzed descriptively. Statistical analyses were carried out using SPSS Statistics 20 and SAS 9.2.

\section{Results \\ Sample}

Table 2 shows the characteristics of all 30 participants and those who completed both questionnaires. Of the 27 participants

Table 2 Characteristics of participants

\begin{tabular}{|c|c|c|}
\hline & $\begin{array}{l}\text { All } \\
\text { participants } \\
(\mathbf{N}=\mathbf{3 0})\end{array}$ & $\begin{array}{l}\text { Participants } \\
\text { completing both } \\
\text { questionnaires } \\
(\mathbf{N}=\mathbf{2 7})\end{array}$ \\
\hline Female, $\mathrm{n}(\%)$ & $21(70.0)$ & $18(66.7)$ \\
\hline Age in years, mean (range) & $50.5(3 I-7 I)$ & $5 I .3(3|-7|)$ \\
\hline \multicolumn{3}{|l|}{ Education, n (\%) } \\
\hline Primary school & $2(6.7)$ & $2(7.4)$ \\
\hline $\begin{array}{l}\text { Upper secondary or } \\
\text { vocational school }\end{array}$ & $7(23.3)$ & $6(22.2)$ \\
\hline Short higher education & $3(10.0)$ & $2(7.4)$ \\
\hline Medium higher education & II (36.7) & II (40.7) \\
\hline Long higher education & $6(20.0)$ & $5(18.5)$ \\
\hline Other educations & $I(3.3)$ & I (3.7) \\
\hline \multicolumn{3}{|l|}{ Household composition, n (\%) } \\
\hline Living alone & $5(16.7)$ & $5(18.8)$ \\
\hline $\begin{array}{l}\text { Living with a partner or } \\
\text { spouse }\end{array}$ & $22(73.3)$ & $19(70.4)$ \\
\hline $\begin{array}{l}\text { Living with children or } \\
\text { adolescents }<20 \text { years old }\end{array}$ & $9(30.0)$ & $7(25.9)$ \\
\hline Living with other adults & $3(10.0)$ & $3(I I . I)$ \\
\hline \multicolumn{3}{|c|}{ Perceived as very or somewhat supportive in diabetes care, $\mathrm{n}(\%)$} \\
\hline Family and friends & $30(100)$ & $27(100)$ \\
\hline Colleagues & $17(56.7)$ & $16(59.3)$ \\
\hline Health care professionals & $27(90)$ & $24(88.9)$ \\
\hline Local community & II (36.7) & $10(37.0)$ \\
\hline \multicolumn{3}{|c|}{ Baseline high of very high diabetes-related social support, n (\%) } \\
\hline $\begin{array}{l}\text { Could contact people } \\
\text { interested in my diabetes } \\
\text { management }\end{array}$ & $21(70.0)$ & $19(70.4)$ \\
\hline $\begin{array}{l}\text { Could contact people } \\
\text { with diabetes to share } \\
\text { experiences about } \\
\text { diabetes management }\end{array}$ & $16(53.3)$ & $15(55.6)$ \\
\hline $\begin{array}{l}\mathrm{HbAlc}(\mathrm{mmol} / \mathrm{mol}) \\
\text { mean }(\text { range })^{\mathrm{a}}\end{array}$ & $58.9(47-72)$ & $58.6(47-69)$ \\
\hline
\end{tabular}

Note: ${ }^{a}$ Excludes HbAlc levels for one participant who was pregnant when she participated in the meetings and gave birth shortly afterward.

Abbreviation: HbAlc, hemoglobinAlc. 
(90\%) completing both questionnaires, 67\% were women. The age and educational level of participants varied. More than two-thirds of participants lived with a partner or spouse, and the majority experienced family, friends, and health care professionals as supporting their diabetes care. Less than half of participants experienced people in the local community as supportive of their diabetes care, and approximately half of the participants experienced colleagues as supportive. Before the peer support meetings, more than half of participants reported having contact with peers or others about diabetesrelated experiences (Table 2). Neither the dropout rate of $10 \%$ (Table 2 ) nor did the dropout of two women who did not participate in interviews (data not shown) cause significant changes in the pattern of patient characteristics.

\section{Topics addressed at peer support meetings}

A variety of topics were addressed during the meetings. Food, physical activity, and functions of the insulin pump were the most frequent topics of discussion. Motivation for changing eating and exercise habits was also discussed. Participants also talked about stress and work life, including blood glucose levels in stressful situations and their preferences for support from employer and colleagues. They discussed individual needs and preferences for diabetes-specific social support from family and friends and worries related to life with diabetes, such as those about high blood glucose and complications. Participants talked about feelings of being dependent on or limited by their diabetes supplies, their individual needs for having supplies in different situations, and worries about forgetting or losing supplies. They shared perspectives on how to wear the pump; for example, one participant described clothes with pockets designed for pump users. Participants discussed diabetes-related challenges on special occasions such as holidays and parties.

\section{Expected effects of peer support meetings} Participants' perception of effects: qualitative findings Participants perceived effects related to 1) experiences of diabetes-specific social capital, 2) motivation and changes in everyday life, 3) awareness of personal diabetes practices and differences among people with type 1 diabetes, 4) serenity and openness in life with diabetes, 5) feeling sad or upset, and 6) awareness of treatment and support possibilities and changes in diabetes treatment. Only three participants reported that they had not experienced anything new during meetings or any subsequent changes. No differences in terms of perceived effects were found between groups, as all themes originated in data from both peer support groups. Table 3 depicts the six themes and example quotes from interviews.

\section{Diabetes-specific social capital}

Some participants perceived effects related specifically to experiencing diabetes-specific social capital. They stated that being able to relate to and identify with other people's daily lives was an important outcome of participating in the peer support meetings. Participants emphasized their experiences of "not being alone" (male), "to have confirmed that others are dealing with some of the same things" (female), "not being the only one struggling" (male), and "type 1 diabetes and life with an insulin pump as normal" (female) when they were asked about the effects of peer support meetings. One man stated

It's a little like being reassured that others deal with some of the same stuff as you do. And in that moment feel that you're not alone. That most of the time we're struggling with the same thoughts, that's somehow comforting.

\section{Motivation and changes in everyday life}

Participants described sharing experiences with people with similar challenges as very motivating for setting goals and leading to practical changes in their everyday lives, eg, trying new settings on the insulin pump and being more physically active. Some participants described the meetings as inspiring them to try out new things related to their diabetes management, such as eating pizza or sushi, changing injection sites more regularly, having a small "to go" diabetes kit, and carrying a small food scale in their handbag. One man described how he changed procedure:

A very concrete thing was how to place the sensors and the insulin. Many peers said they started at the back and then took it all the way around, and then opposite again. I actually found it interesting to hear and I've adopted this.

\section{Awareness of personal diabetes practices and differences} among people with type I diabetes

Participants explained that meeting with peers made them more aware of their own diabetes practices, particularly how they used the pump. Listening to and comparing themselves with others made them more aware of how they managed their diabetes and that some of their practices were not intentional. The meetings initiated reflections among participants regarding what they felt was right for them and what they could do differently. The meetings also raised awareness of the necessity of handling diabetes "in one's own way" (female) 
as participants became aware of differences among people with type 1 diabetes and various situations, such as differences in the effect on blood glucose of stressful situations and how different types of physical activity influenced blood glucose levels. One woman explained:

We have diabetes, we're type 1's, we all have a pump, and yet we're quite different. Some react that way, others react in that way, that was also nice to know.

\section{Serenity and openness in life with diabetes}

Participants reported that they felt calmer and that they could take things more easily after having heard other people's successful experiences or similar difficulties in life with using an insulin pump. The meetings made them aware that "no one is perfect" (female) that they could "be more relaxed" (female) and "stop beating up yourself" (male) "since it doesn't always go according to plan" (female).

Table 3 Themes and example quotes of perceived outcomes

\begin{tabular}{ll}
\hline Themes & Quotes \\
\hline $\begin{array}{l}\text { Diabetes-specific } \\
\text { social capital }\end{array}$ & To have confirmed that others are dealing with some of the same things you are ... and then, in that particular \\
& space feel that you are not alone. That to a great extent you are having the same thoughts. That's nice in some \\
& way. I don't know why [...] [male] \\
& I have learned a lot about how similar we all feel. You know, and that has been the main issue for me, to find out \\
& that it is the same things we struggle with all the time. So those are the conditions when you have diabetes. Uhm, \\
& those are the things we struggle with, meaning that I am not special [female]
\end{tabular}

Motivation and changes in everyday life

It was an epiphany. Wow, it can really vary that much, just because of the injection site. Okay. I have that with me now where I rotate and think ... You know, if I had only known the thing about that place under the navel or something that didn't work. Now I have other zones. [female]

I was discussing exercising with [another participant]. He was a great inspiration to me. You know, I promised him at the third meeting, that the next time we met, I would have started running again. I had started running at that time and I have actually started running regularly since. It really motivated me. [female]

\section{Awareness of own diabetes practice and differences among people with type I diabetes}

Serenity and openness in life with diabetes

Feeling sad or upset
That is also something I think you can take with you from talks like that. That once in a while you think about it and ... well. I always do this in a certain situation, or what it is you do, right. It doesn't have to be like that! [male] Yes, well ... it is slightly embarrassing, but every time as I was leaving I thought - sort of smugly - because there were some things that surprised me. For example, people who had not told their workplace about their diabetes. I think that is completely senseless. I actually felt kind of complacent and smug about how I was open about having diabetes. For me, that confirmed that I was right in doing that - yes. [male] It is a very individual disease in that way ... You have to pay attention to yourself and believe in yourself. [female]

I feel more at ease now because I thought it was only me who had these problems. Now it turns out there were a bunch of others and with that in mind I can kind of say, ok it's not stupid. It gives me a certain ease of mind. [male] I also believe that I have become even more open about my disease when relating to others ... I think it is because - you know, in the course of these four meetings, I have both heard so much and shared quite a few things myself about my diabetes, and that has felt really quite natural. Not to say that it perhaps didn't before, but it is just to a much larger degree now. I really think so. I think that is part of what I learned. Definitely. [female]

I would have wished that it worked for me and that I could just sit and share my experiences and just be together regularly. It actually makes me kind of upset, even more upset than I usually am, when I come and hear how everyone else feels really well. I don't know if they do, that is not how I would put it. They do not all feel great, but they are happy with the pump, most of them. I think so. [female] Then I was at my parents [...] and there was some discussion or I talked about how I was low [in blood glucose] or something - and then I didn't feel like I was being met, and then I thought - then I drew on the reflections I had from the [peer support] meetings. Then I thought: they just don't understand me. It was reinforced in a way - that there was no real understanding. I don't think l've ever felt that ill. [female] There were a few people [at the peer support meetings] who worked part time and that makes me kind of sad, when you are not able to have a full-time job with diabetes. To me, it sounded like that was almost impossible for some people and I know some of them have other illnesses than diabetes, but that made me a bit sad. [female]

Before, I had the sense that it was - I don't know if you can say, I think very troublesome. You know, the pump is a whole new form of treatment and that was also very troublesome, so I sort of felt like - I can't do it. But after the meetings I feel like - there were people there who had had a sensor, but thrown it away because it wasn't for them at all. But on the other hand, there were also people who said that could not imagine life without it and that it had really helped them in a lot of ways. It gave them a sense of comfort - that they were better able to relax in some way. So that made me really, really curious. Afterward, when I was at control at Hvidovre [Hospital] I spoke to my doctor and she said that she thought trying it out was a good idea, too. [female]

After the meetings, I have begun using that app [from the Danish Diabetes Association]. That is a very concrete example of something I have done afterward. [female] 
One woman also felt that talking openly about her diabetes during the meetings had made her more open about sharing diabetes with other people, such as colleagues, because it felt more natural after having an open conversation with peers (female). She said:

Well, I think that it might have helped me to feel a little less lonely. Just ... my mindset may have changed a little, in the sense that of course I should talk about it. It's a part of me.

And it's nothing to be ashamed of. You shouldn't hide it.

\section{Feeling sad or upset}

Some participants mentioned being less worried after attending peer support meetings. However, other participants became more worried about the consequences of diabetes when they saw participants with complications or heard others talk about their complications or difficulties with managing diabetes. A young woman said that it affected her to see others with complications:

It was a bit like, you think, God you're only 36, do you have something with your eyes! There was one person who had a lot of problems with her eyes.

One participant described how discussions during the meetings made her aware of difficulties related to her social contacts and that she consequently felt upset after the meetings (female). One participant (female) reported that the meetings made her sad because she felt all other participants "were much better" and "braver" in managing their diabetes than she was.

\section{Awareness of treatment and support possibilities and changes in diabetes treatment}

Some participants reported that the meetings had made them curious about other treatment possibilities. For example, one participant who had previously felt that it would be too invasive for her to have CGM saw that some participants were very satisfied with continuous monitoring. After the meetings, she initiated CGM. Other participants were not aware that they could have a yearly status consultation with a diabetes nurse; they booked appointments for this after participating in the meetings. Other participants became aware of the importance of having their eyes checked regularly and a woman described:

It was an eye opener that you could have a travel pump. That was what really surprised me the most. Well, I wouldn't have thought of it, not even asked about it, because you bring a pen when you travel and your pump in my world, so I think that was ok to learn.
Some participants also became more aware of Facebook communities and peer support possibilities after talking to other participants.

\section{Relevant effect measures - participant prioritization of quantitative effect measures}

Participants prioritized diabetes management and development of peer networks as the most relevant effects of the peer support meetings. Diabetes loneliness ranked as the third most relevant outcome, followed by well-being and diabetes distress. Participants viewed changes in general loneliness as the least relevant potential effect of the intervention.

\section{The extent of the effects: quantitative analyses}

Quantitative analyses showed no significant differences in HbA1c, well-being, diabetes empowerment, or overall diabetes distress when comparing participants before and after the intervention (Table 4). Initial scores for overall diabetes distress and subdomains were relatively low, but significant improvement was found in eating distress (Table 4). When exploring single T1-DDS items, a tendency to lower postintervention scores was found in items related to powerlessness, including "feeling discouraged when I see high blood glucose numbers I can't explain" (13 participants scored $\geq 3$ at baseline vs six participants after the intervention) and "feeling that no matter how hard I try with my diabetes, it will never be good enough" (13 participants scored $\geq 3$ at baseline vs seven participants after the intervention). A slight tendency to increased diabetes distress after the intervention was observed when exploring a single item related to friends/family: "feeling that my family and friends make a bigger deal out of diabetes than they should" (one participant scored $\geq 3$ at baseline vs five participants after the intervention). When examining single items, analyses showed a trend of increase in diabetes empowerment. Before the meetings, 13 participants reported low empowerment related to the item "In general, I believe that I can try out different ways of overcoming barriers to my diabetes goals"; after the intervention, only nine participants reported low empowerment for this item. After the intervention, participants significantly more seldom felt that they lacked someone to talk to about diabetes and more participants "rarely felt isolated from others". Furthermore, significantly more participants found "other people with type 1 diabetes very/somewhat supportive in diabetes care" after the intervention. Other nonsignificant tendencies toward decreased diabetes loneliness were found $(P=0.10)$. 
Table 4 Baseline and postintervention $\mathrm{HbAlc}$, well-being, diabetes empowerment, diabetes distress, loneliness, and social support

\begin{tabular}{|c|c|c|c|}
\hline & Baseline $(\mathbf{N}=\mathbf{2 7})$ & Postintervention $(\mathbf{N}=\mathbf{2 7})$ & $P$-values ${ }^{a}$ \\
\hline $\mathrm{HbAlc}(\mathrm{mmol} / \mathrm{mol})$, mean (range) ${ }^{\mathrm{b}}$ & $58.6(47-69)$ & $58.0(47-67)$ & 0.41 \\
\hline WHO-5 score, mean & 62.2 & 63.6 & 0.67 \\
\hline DES-SF score <4, n (\%) & $18(66.7)$ & $18(66.7)$ & 0.49 \\
\hline \multicolumn{4}{|l|}{ TI-DDS score $\geq 3$, n (\%) } \\
\hline Overall distress & $2(7.4)$ & I (3.7) & 0.27 \\
\hline Powerlessness & $6(22.2)$ & $6(22.2)$ & 0.08 \\
\hline Negative social perceptions & $2(7.4)$ & $2(7.4)$ & $\mathrm{NA}^{\mathrm{c}}$ \\
\hline Physician distress & I (3.7) & I (3.7) & $\mathrm{NA}^{\mathrm{c}}$ \\
\hline Friend/family distress & I (3.7) & $0(0)$ & 0.73 \\
\hline Hypoglycemia distress & $4(14.8)$ & $4(14.8)$ & 0.89 \\
\hline Management distress & $3(11.1)$ & $3(11.1)$ & 0.18 \\
\hline Eating distress & $10(37.0)$ & $7(25.0)$ & $<0.001$ \\
\hline \multicolumn{4}{|l|}{ Loneliness and social support, $\mathrm{n}(\%)$} \\
\hline $\begin{array}{l}\text { Other people with type I diabetes are very/ } \\
\text { somewhat supportive in diabetes care }\end{array}$ & $15(55.6)$ & $20(74.1)$ & $<0.001$ \\
\hline Rarely feel isolated from others & $19(70.4)$ & $20(74.1)$ & 0.003 \\
\hline Rarely feel starved for company & $20(74.1)$ & $20(74.1)$ & 0.12 \\
\hline Rarely feel left out & $24(88.9)$ & $24(88.9)$ & 0.15 \\
\hline Rarely miss someone to talk to about diabetes & $8(29.6)$ & $14(51.9)^{\mathrm{a}}$ & $<0.001$ \\
\hline Rarely feel lonely with diabetes & $10(37.0)$ & $12(46.2)$ & 0.10 \\
\hline
\end{tabular}

Notes: ${ }^{a}$-values from the Wilcoxon signed-rank test (binary outcomes) and paired $t$-tests (linear outcomes). ${ }^{b}$ Excludes HbAlc levels for one participant who was pregnant when she participated in the meetings and gave birth shortly afterward. 'No discordant pairs.

Abbreviations: DES-SF, Diabetes Empowerment Scale-Short Form; HbAIc, hemoglobin AIC; TI-DDS, Type I Diabetes Distress Scale; WHO-5, 5-item World Health Organization Well-Being Index.

After the intervention, participants reported receiving support from peers more frequently and more participants rarely felt lonely with diabetes, compared to baseline (Table 4). No differences in generic loneliness were found.

\section{Perceived effects: characteristics of the intervention and participants}

The highly diverse nature of the groups and how participants perceived the diversity influenced the effects of the intervention. Participants who did not feel that they were like the others in the group or felt that they could not relate to other participants experienced minimally positive, negative, or no effect of the peer support meetings. One young woman felt that she could not discuss certain issues, such as pregnancy, and also did not feel connected to the others in the group. Some participants referred to difficulties in engaging in meaningful dialogues because of differences in the educational level of participants, and others referred to a "lack of chemistry" (female), "different approaches to handling diabetes" (male), "others were better" (female), or "some people didn't fit into the group at all" (female). Some participants reported that they would have preferred to discuss topics such as sex and the influence of hormonal changes on glucose levels in separate groups for men and women. However, other participants found that the diversity in the group was helpful in providing insights into an array of different diabetes practices.

The format of the intervention, in which participants prioritized topics for the meetings, also influenced the perceived effects. In some cases, participants felt that the majority decided what topics were addressed that no one wanted to discuss what was especially important to them or both. Lack of structured involvement of health care professionals and professional input, such as guidelines for physical activities for patients using insulin pumps, was also identified by some participants as associated with their experiences of limited effects of peer support.

Participants with previous peer support experiences or regular contact with peers did not find the peer support meetings as helpful or insightful as those who had no peer support experiences. One participant stated that she realized she was tired of diabetes in the sense that she was tired of hearing herself saying the same things.

Another factor associated with the perceived effects of the peer support meetings was the reasons that participants joined them. Some people decided to participate because they wanted to have contact with peers, and they expected to share experiences and to feel less alone with diabetes as a result. Others participated to obtain new "professional" knowledge about diabetes and the insulin pump to become motivated for improving their self-management, or because they wanted 
to support diabetes-related research projects. Others chose to participate because the peer support meetings targeted only insulin pump users or because they were organized and facilitated by a health care professional. Individuals who did not participate primarily to meet and discuss their self-management with peers more frequently described experiencing no, little, or negative effect, compared to participants who were seeking peer contact.

\section{Discussion}

The aim of this study was to explore the effects of a flexible and participatory peer support intervention in a clinical setting for adults with type 1 diabetes treated with an insulin pump, focusing on enhancing diabetes-specific social capital. The key questions were as follows: 1) what effects are appropriate to expect, according to participants? and 2) to what extent did these effects occur? In the pilot test of the peer support intervention, most participants experienced diabetes-specific social capital, became more aware of personal diabetes practices and motivated to make changes, felt increased serenity in relation to diabetes, and were less worried after attending the meetings. There was a significant reduction in the number of participants who felt that they lacked someone to talk to about diabetes and a significant increase in perceived support from peers and significantly lower eating distress. Furthermore, tendencies toward higher empowerment, lower powerlessness (diabetes distress), and decreased diabetes loneliness were found. However, some participants did not find the intervention helpful and a few felt more distressed after the meetings or were distressed about new topics raised during the meetings. The intervention had no effect on glycemic control and well-being (measured quantitative). These findings corresponded well with the topics that were addressed at the meetings and the finding that participants identified diabetes management and development of peer networks as the most relevant outcomes.

The study indicated several reasons for not finding the meetings helpful. Some participants may not have needed diabetes-specific social support, as they stated that they had other peer contacts. Others did not see meeting with peers as a main purpose of attending, and therefore, the output of the meeting did not live up to their expectations. Those who felt that the group was not a unit or that important topics were not addressed also had fewer positive outcomes, more negative outcomes, or both. Peer support can provide a space for role modeling ${ }^{11}$ and thereby improve participants' selfefficacy - their confidence in own abilities. ${ }^{30}$ However, the study indicated that people who have very little confidence in their own abilities with regard to diabetes management (low self-efficacy) find it challenging to mirror themselves in other more confident participants. Likewise, people that seemed very confident in their diabetes management (high self-efficacy) were not as receptive to other participants' experiences.

Studies of peer support include variations in who provides peer support. ${ }^{31}$ Facilitators include peers/lay people alone, peers working with professionals, or professionals facilitating groups of peers. ${ }^{31}$ Few studies have compared support from peers alone to professional-led peer support. Studies that do so find peer and professional facilitators equally effective at facilitating peer-to-peer emotional or social support. ${ }^{31}$ As the premise of peer support is to promote and strengthen social support between peers, ${ }^{11}$ some may argue that health care professionals do not have a role in peer support. Literature related to peer support in diabetes also shows a tendency to conflate diabetes-specific peer support with educational or self-management programs building on health care professionals' understanding of support. ${ }^{10}$ This may create doubt about the role of health care professionals in peer support. Peer support can be viewed as a continuum: a set of different interventions that can be integrated into a variety of settings and services, ranging from those that include no involvement from health care professionals (eg, Facebook groups) to peer support integrated into clinical practice (Peers for Progress, unpublished report).

However, when peer support occurs outside of clinical practice, there is no guarantee that it is available to people with diabetes. The link to the professional system can broaden the scope of peer support. Our pilot study showed that, among people receiving insulin pump treatment, peer support initiated in a clinical setting with facilitation by a health care professional created an effective space for peer support. The novelty of this study lies in the fact that the meetings were very flexible, did not aim to provide formal patient education, and were guided by participants' perspectives on what should be addressed and discussed. The meetings were conducted in a clinical setting by a health care professional who was instructed to focus on experience sharing, that is, guiding participants to respond to each other's questions.

The intervention enhanced diabetes-specific social capital and confirmed the previous study of patient preferences for peer support among adults with type 1 diabetes. ${ }^{15}$ The intervention showed potential to support people with type 1 diabetes and insulin pumps, consistent with what has previously been defined as the key functions of peer support by Peers for Progress: 1) assistance in daily management, 2) social and emotional support, 3) linkage to clinical care and community resources, and 4) ongoing support of chronic 
disease management. ${ }^{32}$ The intervention showed potential to have benefits similar to those of more extensive programs. ${ }^{12}$ However, its potential to reduce diabetes distress needs to be explored further, due to the fact that not many of the participants experienced high distress at baseline.

Although participants often emphasized practical guidance in relation to perceived outcomes and many of the topics during meetings seemed very practical, indicators of emotional support and the potential to reduce distress were observed. Practical and emotional support fused during the meetings, eg, when a participant gave practical advice while holding another participant's pump. This also gave participants a feeling of normality and cohesion. Other studies have also shown that emotional support often is implicit and can emerge from instrumental support. ${ }^{32}$ Some participants became aware of issues that they had not thought about before attending the meeting and therefore felt more distressed. However, enhanced awareness of problems is not necessarily a negative outcome, because it may be followed by changes in problem areas.

This study makes important contributions to the literature: patient perspectives on effects of peer support, usefulness of peer support, and effective types of peer support. The key findings are that the support has to be relevant in terms of timing, expectations, topics, and participants; some participants reported that they missed guidance from health care professionals and may have had more benefit from a mix of peer support and more formal patient education approaches. We found that group composition and dynamics were important to the effect of peer support; its relevance may be enhanced when targeting subgroups of people with diabetes, such as those with insulin pumps, as in our study. However, our findings also indicated that people using insulin pumps may also benefit from meeting in gender- or age-defined subgroups. Other studies have shown that the more homogeneous peer groups are, the more likely it is that participants feel understood and exchange mutual help. ${ }^{33,34}$

Strengths of our study include the use of various methods that increase the robustness of the results. ${ }^{35} \mathrm{We}$ also included a variety of participants with differences in gender, age, educational level, marital status, and prior peer support experiences. There was minimal dropout over the course of the four meetings, and $>80 \%$ of participants were interviewed. Meaning saturation in qualitative data collection can be reached with 16-25 interviews. ${ }^{36}$ Interview analyses indicated that data saturation was reached when data began to repeat findings and no additional issues were identified while coding the final few interviews. Individual interviews increased the likelihood that participants were open during interviews and provided in-depth descriptions of personal experiences $^{37}$ and the semistructured interview guide focused the interviews on participants' perceived effects. A limitation of our study is the relatively small population; it limited the statistical power of quantitative analyses and our ability to detect differences over time. Nevertheless, the quantitative data provide some insight into potential effects of peer support interventions among patients with type 1 diabetes using insulin pump therapy and into the effects that patients consider most relevant, both of which should be studied further, eg, it would be relevant to explore if there are other more relevant measures to capture participants' improved motivation, changes in everyday life, and feeling of serenity in life with diabetes. It is difficult to generalize based on this single pilot study. The findings are related to the context of the intervention such as the characteristics of the facilitators and participants and the clinical setting. Further pilot studies are needed to determine appropriate and relevant quantitative effect measures and to estimate specific effects of similar interventions in larger scale studies.

\section{Conclusion}

This study provides insight for future intervention studies in peer support. The flexible and participatory peer support approach increased diabetes-specific social capital, enhanced diabetes motivation and empowerment, created a feeling of serenity about diabetes management, and showed potential to decrease diabetes distress. Awareness of participants' incentives for attending peer support and the risk of participants feeling isolated within peer support groups is essential for creating effective diabetes-specific social support. Measures that capture motivation, serenity in life with diabetes, awareness of own diabetes practices, diabetes empowerment, diabetes loneliness, and diabetes distress are useful, feasible, and appropriate when measuring the effect of peer support in adults with insulin pump-treated diabetes.

\section{Acknowledgments}

The authors acknowledge Mathilde Overgaard and Astrid Schultz, Steno Diabetes Center Copenhagen, Diabetes Management Research, for research assistance. We also thank all the participants for their participation in the study.

\section{Disclosure}

MMA is currently employed at Department of Endocrinology, Nordsjællands Hospital, Hillerød, Denmark. The authors report no other conflicts of interest in this work.

\section{References}

1. Beck RW, Tamborlane WV, Bergenstal RM, et al; T1D Exchange Clinic Network. The T1D exchange clinic registry. J Clin Endocrinol Metab. 2012;97(12):4383-4389. 
2. Selam JL. CSII in Europe: where are we, where are we going? An analysis of articles published in Infusystems International. Diabetes Res Clin Prac. 2006;74:S123-S126.

3. Hodgson S, Beale L, Parslow RC, Feltbower RG, Jarup L. Creating a national register of childhood type 1 diabetes using routinely collected hospital data. Pediatr Diabetes. 2012;13(3):235-243.

4. Pozzilli P, Battelino T, Danne T, Hovorka R, Jarosz-Chobot P, Renard E. Continuous subcutaneous insulin infusion in diabetes: patient populations, safety, efficacy, and pharmacoeconomics. Diabetes Metab Res Rev. 2016;32(1):21-39.

5. Joshi M, Choudhary P. Multiple daily injections or insulin pump therapy: choosing the best option for your patient - an evidence-based approach. Curr Diab Rep. 2015;15(10):81.

6. Sturt J, Dennick K, Due-Christensen M, McCarthy K. The detection and management of diabetes distress in people with type 1 diabetes. Curr Diab Rep. 2015;15(11):1-14.

7. Joensen LE, Almdal TP, Willaing I. Type 1 diabetes and living without a partner: psychological and social aspects, self-management behaviour, and glycaemic control. Diabetes Res Clin Pract. 2013;101(3): 278-285.

8. Lloyd CE, Wing RR, Orchard TJ, Becker DJ. Psychosocial correlates of glycemic control: the Pittsburgh epidemiology of diabetes complications (EDC) study. Diabetes Res Clin Pract. 1993;21(2-3):187-195.

9. World Health Organization. World Health Report 2007: Peer Support Programs in Diabetes. Geneva: WHO; 2008.

10. Simmons D, Bunn C, Cohn S, Graffy J. What is the idea behind peerto-peer support in diabetes? Diabetes Manage. 2013;3(1):61-70.

11. Dennis CL. Peer support within a health care context: a concept analysis. Int J Nurs Stud. 2003;40(3):321-332.

12. Due-Christensen M, Zoffmann V, Hommel E, Lau M. Can sharing experiences in groups reduce the burden of living with diabetes, regardless of glycaemic control? Diabet Med. 2012;29(2):251-256.

13. Markowitz JT, Laffel LM. Transitions in care: support group for young adults with Type 1 diabetes. Diabet Med. 2012;29(4):522-525.

14. Joensen LE, Almdal TP, Willaing I. Associations between patient characteristics, social relations, diabetes management, quality of life, glycaemic control and emotional burden in type 1 diabetes. Prim Care Diabetes. 2016;10(1):41-50.

15. Joensen LE, Filges T, Willaing I. Patient perspectives on peer support for adults with type 1 diabetes: a need for diabetes-specific social capital. Patient Prefer Adherence. 2016;10:1443.

16. Mattelmäki T. Applying probes-from inspirational notes to collaborative insights. CoDesign. 2005;1(2):83-102.

17. Crabtree A, Hemmings T, Rodden T, et al [webpage on the Internet]. Designing with Care: Adapting Cultural Probes to Inform Design in Sensitive Settings; 2006. Available from: http://citeseerx.ist.psu. edu/viewdoc/summary?doi=10.1.1.67.9650. Accessed September 25, 2017.

18. Piette JD, Resnicow K, Choi H, Heisler M. A diabetes peer support intervention that improved glycemic control: mediators and moderators of intervention effectiveness. Chronic Illn. 2013;9(4):258-267.

19. Craig P, Dieppe P, Macintyre S, et al. Developing and evaluating complex interventions: the new Medical Research Council guidance. BMJ. 2008;337:a1655.
20. Bech P, Gudex C, Staehr Johansen K. The WHO (Ten) well-being index: validation in diabetes. Psychother Psychosom. 1996;65(4):183-190.

21. Hajos TRS, Pouwer F, Skovlund SE, et al. Psychometric and screening properties of the WHO-5 well-being index in adult outpatients with Type 1 or Type 2 diabetes mellitus. Diabet Med. 2013;30(2):e63-e69.

22. Fisher L, Polonsky WH, Hessler DM, et al. Understanding the sources of diabetes distress in adults with type 1 diabetes. J Diabetes Complications. 2015;29(4):572-577.

23. Anderson RM, Fitzgerald JT, Gruppen LD, Funnell MM, Oh MS. The diabetes empowerment scale-short form (DES-SF). Diabetes Care. 2003;26(5):1641-1642.

24. Nicolucci A, Kovacs Burns K, Holt RIG, et al. Diabetes attitudes, wishes and needs second study (DAWN2): cross-national benchmarking of diabetes-related psychosocial outcomes for people with diabetes. Diabet Med. 2013;30(7):767-777.

25. Hughes ME, Waite LJ, Hawkley LC, Cacioppo JT. A short scale for measuring loneliness in large surveys: results from two populationbased studies. Res Aging. 2004;26(6):655-672.

26. Lasgaard M, Friis K, Shevlin M. "Where are all the lonely people?" A population-based study of high-risk groups across the life span. Soc Psychiatry Psychiatric Epidemiol. 2016;51(10):1373-1384.

27. Barrera M Jr, Glasgow RE, McKay HG, Boles SM, Feil EG. Do internet-based support interventions change perceptions of social support? An experimental trial of approaches for supporting diabetes self-management. Am J Community Psychol. 2002;30(5):637-654.

28. Christensen AI, Ekholm O, Glümer C, et al. The Danish National Health Survey 2010. Study design and respondent characteristics. Scand J Public Health. 2012;40(4):391-397.

29. Malterud K. Systematic text condensation: a strategy for qualitative analysis. Scand J Public Health. 2012;40(8):795-805.

30. Bandura A. Self-efficacy: toward a unifying theory of behavioral change. Psychol Rev. 1977;84(2):191-215.

31. Nesta. Peer Support: What Is It and Does It Work? London: Nesta; 2015 .

32. Fisher EB, Ayala GX, Cherrington A, et al; Peers for Progress Investigator Group. Contributions of peer support to health, health care, and prevention: papers from Peers for Progress. Ann Fam Med. 2015;13(suppl 1): S2-S8.

33. Heisler M. Overview of peer support models to improve diabetes selfmanagement and clinical outcomes. Diabetes Spectr. 2007;20(4):214.

34. Helgeson VS, Cohen S, Schulz R, Yasko J. Group support interventions for women with breast cancer: who benefits from what? Health Psychol. 2000;19(2):107-114

35. Patton MQ. Qualitative Research and Evaluation Methods. 3rd ed. California: Sage Publications; 2002.

36. Hennink M, Kaiser B, Marconi V. Code saturation versus meaning saturation: how many interviews are enough? Qual Health Res. 2016; 27(4):1-18.

37. Kvale S. Interviews - An Introduction to Qualitative Research Interviewing. Thousand Oaks, CA: SAGE; 1996.

38. Engelund G, Vinther-Andersen, Hansen UM, Willaing I. In balance with chronic illness. Tools for patient education. Gentofte, Denmark, Steno Diabetes Center Copenhagen, 2011.
Patient Preference and Adherence

\section{Publish your work in this journal}

Patient Preference and Adherence is an international, peer-reviewed, open access journal that focuses on the growing importance of patient preference and adherence throughout the therapeutic continuum. Patient satisfaction, acceptability, quality of life, compliance, persistence and their role in developing new therapeutic modalities and compounds to optimize

\section{Dovepress}

clinical outcomes for existing disease states are major areas of interest for the journal. This journal has been accepted for indexing on PubMed Central. The manuscript management system is completely online and includes a very quick and fair peer-review system, which is all easy to use. Visit http://www. dovepress.com/testimonials.php to read real quotes from published authors. 